\title{
Fifty Years of the Best of Investigative Radiology
}

\author{
Val M. Runge, $M D$
}

\begin{abstract}
2 015 Is the 50th anniversary, with regard to publication, for Investigative Radiology. It marks as well the 22nd year for which I have had the honor to be the editor-in-chief. Following the lead of its prestigious former editors, the journal continues to focus on cutting edge research, with an emphasis on technological innovation that affects clinical diagnostic imaging. During this timeframe, the journal has seen great success, with the rise in impact factor (granted an imperfect measure) from a rating of 0.712 in 1995 to 4.453 in 2013 (the most current year available). The journal during these 2 decades has also improved rankwise from being in the middle (on the radiology, nuclear medicine, and medical imaging list) to number 2, the latter rank being specifically for journals publishing the breadth of diagnostic imaging. In selectivity, the journal is also at its peak, with only $12 \%$ of manuscripts submitted eventually accepted for publication. Unfortunately, this does mean that many excellent research articles are not able to be included. The journal is very much in debt to the many outstanding research groups across the world that have contributed their work and to the many reviewers who donated their time and expertise, together with the members of the editorial board from across the world who provided guidance and leadership. During the past 20 years, the journal has also evolved from one in which the focus was on research from institutions in the United States to one which routinely publishes articles from the major radiology departments across the world that are actively involved in leading edge research. It should be noted that this has occurred in concert with an unparalleled expansion in clinical imaging capabilities, which has had major impact on the importance of diagnostic imaging clinically, and its use.

It is of interest in considering the history and evolution of the journal (and indeed the field of diagnostic imaging itself) to compare the top 10 cited articles from the 25 th anniversary issue publication $^{1}$ to that of today. Two articles involved bone mineral quantitation, which today is a widely used, accepted clinical test. Four articles involved clinical areas that with time were co-opted by other medical specialties, reflecting on the evolution of diagnostic imaging itself. One article reported on intravenous contrast media, a continued focus of the journal. Two other eminent publications involved the imaging of flow by magnetic resonance and receiver operating characteristic analysis. Today, the top cited articles reflect the current focus of the journal and indeed of leading edge research and development worldwide in our field. Topics include (in rank order from the number 1 cited publication to number 10) the properties of the gadolinium chelates, ${ }^{2}$ microbubble contrast agents, ${ }^{3}$ reducing radiation dose with computed tomography (CT), ${ }^{4}$ dual-energy CT, ${ }^{5}$ magnetic resonance (MR) imaging at $3 \mathrm{~T}^{6}$ and time-resolved MR angiography. ${ }^{7}$ As described in the 1990 publication, Investigative Radiology "has filled a unique, previously vacant niche in radiology," being "a vehicle for serious basic and clinical investigators to publish imagingrelated research" and in so doing, improved the credibility of radiology researchers and broadened their participation in research funding and worldwide medical research.

The anniversary issue of the journal focuses on research (reflecting the very basis of the journal), specifically on the current top fields in clinical imaging, state of the art, and future directions. I am indebted to 10 tremendous academicians, principally board members, who are leading stars in their respective fields and who have devoted the time and energy to write extremely valuable essays in each of these areas. The subjects include brain, lung cancer, cardiovascular imaging, abdominal MR and CT, prostate cancer, internal derangement of the joints, breast cancer, CT technology, MR technology, ultrasound, and contrast media for X-ray and MR. Their articles are likely for years to come to have a major impact and provide valuable insight and guidance to researchers in these areas. Although Investigative Radiology publishes a relatively small number of articles each year, it ranks today, and indeed throughout the past decade, among the top cited imaging journals. Its unique mission continues to be, as stated in the 25 th anniversary issue, to publish the very best investigative, basic and clinical imaging-related research.
\end{abstract}

Received for publication March 25, 2015; and accepted for publication, after revision, March 26, 2015.

From the University Hospital Zurich, Zurich, Switzerland.

Conflicts of interest and sources of funding: none declared.

Correspondence to: Val M. Runge, MD, University Hospital Zurich, Zurich, Switzerland. E-mail: ValMurray.Runge@usz.ch.

Copyright $(C) 2015$ Wolters Kluwer Health, Inc. All rights reserved.

ISSN: 0020-9996/15/5009-0549

DOI: $10.1097 /$ RLI.0000000000000165 


\section{REFERENCES}

1. Hillman BJ. Twenty-five years of the best of Investigative Radiology. Invest Radiol. 1990;25:347-350.

2. Rohrer M, Bauer H, Mintorovitch J, et al. Comparison of magnetic properties of MRI contrast media solutions at different magnetic field strengths. Invest Radiol. 2005;40:715-724.

3. Klibanov AL. Microbubble contrast agents: targeted ultrasound imaging and ultrasound-assisted drug-delivery applications. Invest Radiol. 2006;41: 354-362.
4. Prakash P, Kalra MK, Kambadakone AK, et al. Reducing abdominal CT radiation dose with adaptive statistical iterative reconstruction technique. Invest Radiol. 2010;45:202-210.

5. Graser A, Johnson TR, Bader M, et al. Dual energy CT characterization of urinary calculi: initial in vitro and clinical experience. Invest Radiol. 2008;43:112-119.

6. Frayne R, Goodyear BG, Dickhoff P, et al. Magnetic resonance imaging at 3.0 Tesla: challenges and advantages in clinical neurological imaging. Invest Radiol. 2003;38:385-402.

7. Fink C, Ley S, Kroeker R, et al. Time-resolved contrast-enhanced three-dimensional magnetic resonance angiography of the chest: combination of parallel imaging with view sharing (TREAT). Invest Radiol. 2005;40:40-48. 